\title{
Sexual Dimorphism of Bizygomatic distance \& Maxillary sinus using CT Scan
}

\author{
Massarat Jehan ${ }^{1}$, Vipendra Bhadkaria ${ }^{2}$, Akhilesh Trivedi ${ }^{2}$, S.K.Sharma ${ }^{3}$. \\ ${ }^{I}$ Post Graduate Student, Dept of Anatomy, Gajra Raja Medical College, Gwalior (MP) India. \\ ${ }^{2}$ Assistant professor, Dept of Anatomy, Gajra Raja Medical College, Gwalior (MP) India. \\ ${ }^{3}$ Associate professor (HOD), Dept of Anatomy, Gajra Raja Medical College, Gwalior (MP) India.
}

\begin{abstract}
An incomplete skeleton especially skull is a great challenge for Forensic anthropologists for age \& sex estimation. But sometimes denser bones are often recovered intact eg. zygomatic bone, maxillary sinus. Therefore this study tries to use the alternate methods for gender estimation by using measurements of denser areas of such unknown skull especially bizygomatic distance.The aim of this study was to investigate whether the bizygomatic distance, AP diameter \& width of the maxillary sinus \& intermaxillary distance could be used for determination of gender using CT scan. 191 cases were studied, from M.P. region, of which 106 were males and 85 were females. All the measurements were taken from series of CT Head images in axial images on DICOM viewing software in computer.The data was statistically analyzed by using Graph pad prism.Unpaired Student t-test was carried out and calculated for each data separately. Analysis of variance was also done \& F-value were calculated. A statistically significant difference with $p<0.0001$ was observed in the bizygomatic distance with mean $\pm S D$ of $9.55 \pm 0.41 \mathrm{~cm}$ for male \& $9.262 \pm 0.52$ for female. The strongest correlated variable with bizygomatic distance was the intermaxillary distance $(r=0.3037)$ in male \& AP diameter of sinus $(r=0.5980)$ in female. We can conclude that Computerized Tomography measurements of bizygomatic distance \& maxillary sinus dimensions may be useful to support gender determination in forensic medicine when other methods are inconclusive.
\end{abstract}

Keywords: Computerized tomography, Bizygomatic distance, maxillary sinus, Intermaxillary distance, Axial view.

\section{Introduction}

Comparison of ante mortem and post-mortem medical records, such as dental documents, plays an important role in the identification of corpses. However, typical identification methods may be inconclusive, especially when certain extreme post-mortem changes have developed [1]. Although development and progress in various diagnostic methods, but still identification of remnants of skeletal and decomposing parts of human is one of the most difficult skills in forensic medicine. Gender and age estimation is also considering an important problem in the identification of unknown skull [2]. Because most bones that are conventionally used for sex determination (skull, pelvis \& long bones etc.) are often recovered either in a fragmented or incomplete state, it has become necessary to use denser bones that are often recovered intact, eg. the maxillary sinus [3]. Therefore it is important for alternate areas of the skeleton to be researched for gender estimation. It has been reported that zygomatic bones \& maxillary sinus remains intact although the skull \& other bones may be badly disfigured in victims. Measurements of the maxillary sinus in computerized tomography (CT) scans can be used for determination of age and gender when other methods are inconclusive [4]. The axial, sagittal and coronal sections obtained by $\mathrm{CT}$ and MR enable better evaluation of these structures [5].

\section{Selection criteria :}

\section{Materials \& Methods}

It was an observational study in which 191 cases of normal (as diagnosed by the Radiologists) CT Head \& PNS (Paranasal Sinus) scan were studied from M.P. region, of which 106 were males and 85 were females, in the age group of 20-70 years. All the measurements were taken from series of CT Head images in axial view on DICOM viewing software in computer.

\section{Exclusion criteria :}

Any Head \& PNS radiography with obvious pathology or Trauma, facial asymmetry or septal deviation or who had previously undergone surgical procedures or with cleft palate \& supernumerary teeth were excluded from the study. Also the patients with myotonic dystrophy, Fragile X syndrome were excluded. 


\section{The Materials :}

All the patients were examined on Siemens Emotion 16 (16 slice) Multi Detector Spiral Computed Tomography Scanner. The measurements of AP \& width maxillary air sinus, intermaxillary distance \& Bizygomatic dimensions were done directly on computer on DICOM images using Electronic Caliper inbuilt in the DICOM viewer software.

\section{Methodology :}

The greatest measurement were taken after going through different slices in axial view. Parameters measured on CT Head \& PNS were as follows:

1- The Bizygomatic distance was measured on axial reconstructed image \& was defined as the maximum distance between the most prominent points on the right \& left zygomatic arches. ( Fig. 1)

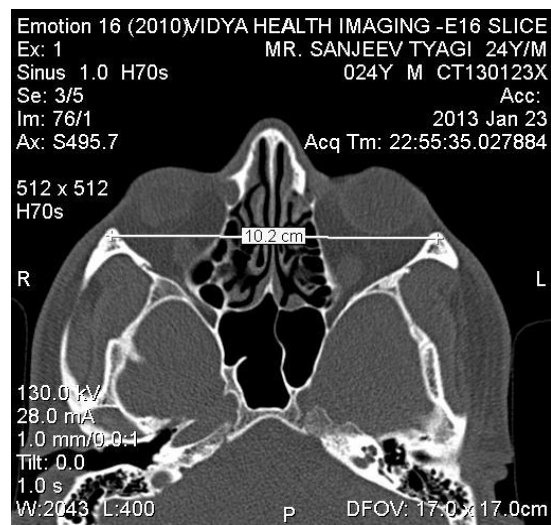

Fig. 1: Axial view showing maximum Bizygomatic distance.

2- The Intermaxillary distance was measured on axial reconstructed image $\&$ was defined as the maximum distance between medial walls of right \& left maxillary air sinuses.( Fig. 2)

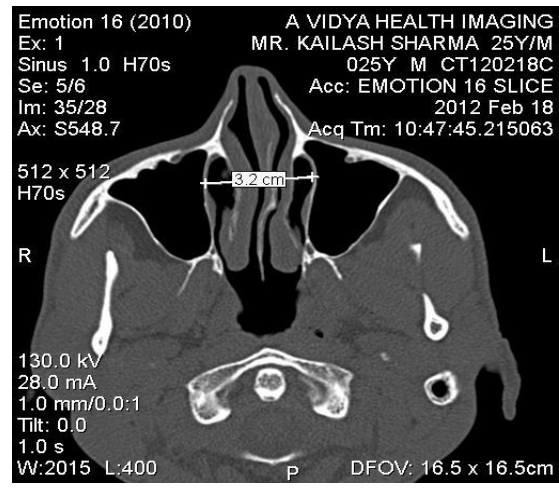

Fig. 2: Axial view showing maximum Intermaxillary distance.

3- The Antero-Posterior dimension was measured on Axial reconstructed image \& was defined as the longest distance anteroposteriorly from the most anterior point to the most posterior point.(Fig. 3)

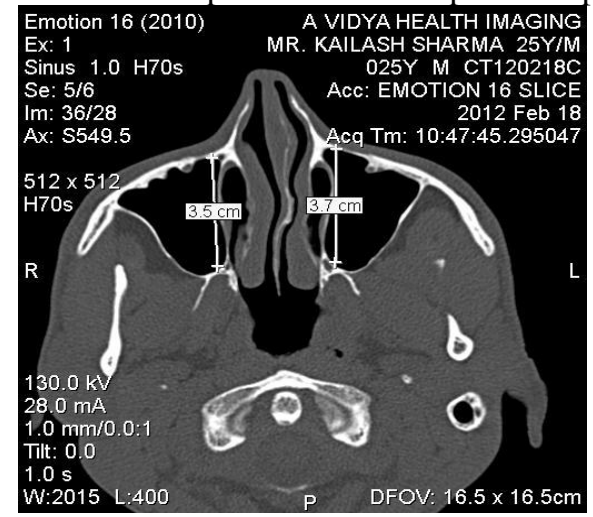

Fig. 3: Axial view showing maximum Right \& Left maxillary sinus AP diameter. 
4- The Width was measured on axial reconstructed image \& was defined as the longest distance perpendicular from the medial wall of the sinus to the outermost point of lateral wall of the lateral process of the maxillary sinus.( Fig. 4)

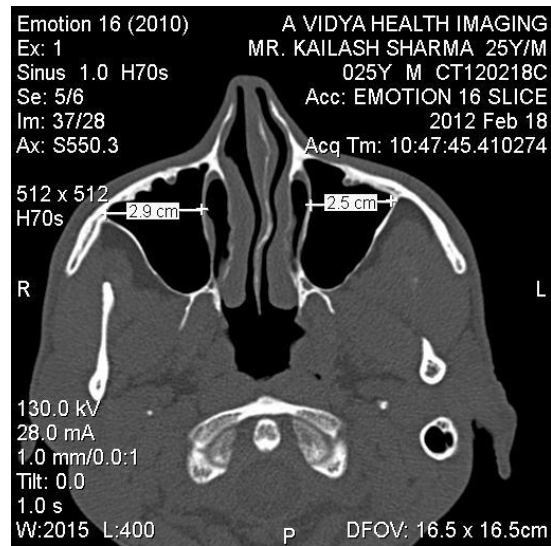

Fig. 4: Axial view showing maximum Right \& Left maxillary sinus Width.

\section{Statistical Evaluation:}

Unpaired Student t-test was carried out and the mean values, SD and $\mathrm{p}$ values of biometrical measurements belonging to Bizygomatic distance \& also the Intermaxillary distane, AP diameter \& width of the maxillary sinus were calculated separately. Analysis of variance was also done between the datas \& F- value were calculated. The statistical analysis were performed by using Graph Pad Prism software.

\section{Results}

The statistical results were shown in Table $1 \& 2$. The Table 1 suggests that the bizygomatic distance was statistically significant $(\mathrm{p}<0.001) \&$ can be used for gender estimation but intermaxillary distance was not significant statistically. Table 2 shows the statistics \& average dimensions of maxillary sinus, which was significant statistically for AP diameter of sinus but not significant for sinus width.

Table 1: Showing statistics of Bizygomatic \& Intermaxillary distance.

\begin{tabular}{|c|c|c|c|c|}
\hline \multirow[t]{2}{*}{ Statistics } & \multicolumn{2}{|c|}{$\begin{array}{l}\text { Bizygomatic distance } \\
\text { (in cm) }\end{array}$} & \multicolumn{2}{|c|}{$\begin{array}{l}\text { Intermaxillary distance } \\
\text { (in cm) }\end{array}$} \\
\hline & Male & Female & Male & Female \\
\hline $\mathrm{N}$ & 106 & 85 & 106 & 85 \\
\hline Mean \pm SD & $9.55 \pm 0.41$ & $\begin{array}{l}9.26 \pm \\
0.52\end{array}$ & $\begin{array}{l}3.29 \pm \\
0.27\end{array}$ & $3.26 \pm 0.28$ \\
\hline Mean \pm SEM & $9.551 \pm 0.03964$ & $9.262 \pm 0.05611$ & $3.290 \pm 0.02654$ & $3.260 \pm 0.03009$ \\
\hline$P$ value(Two-tailed) & \multicolumn{2}{|l|}{$\mathrm{P}<0.0001$} & \multicolumn{2}{|l|}{0.4605} \\
\hline $\mathrm{P}$ value summary & \multicolumn{2}{|l|}{$* * *$} & \multicolumn{2}{|l|}{ Ns } \\
\hline Difference between means & \multicolumn{2}{|l|}{$0.2886 \pm 0.06695$} & \multicolumn{2}{|l|}{$0.02962 \pm 0.04005$} \\
\hline $\begin{array}{l}\text { Are means signif. different? } \\
(\mathrm{P}<0.05)\end{array}$ & \multicolumn{2}{|l|}{ Yes } & \multicolumn{2}{|l|}{ No } \\
\hline $\mathrm{t}, \mathrm{df}$ & \multicolumn{2}{|l|}{$\mathrm{t}=4.310 \mathrm{df}=189$} & \multicolumn{2}{|l|}{$\mathrm{t}=0.7396 \mathrm{df}=189$} \\
\hline $95 \%$ confidence interval & \multicolumn{2}{|l|}{0.1574 to 0.4198} & \multicolumn{2}{|l|}{-0.04888 to 0.1081} \\
\hline R squared & \multicolumn{2}{|l|}{0.08951} & \multicolumn{2}{|l|}{0.002886} \\
\hline $\begin{array}{l}\text { Average }(\mathrm{M}+\mathrm{F}) \\
\text { Mean } \pm \mathrm{SD}\end{array}$ & \multicolumn{2}{|l|}{$9.41 \pm$} & \multicolumn{2}{|l|}{$3.27 \pm$} \\
\hline \multicolumn{5}{|l|}{ F test to compare variances } \\
\hline F,DFn, Dfd & \multicolumn{2}{|l|}{$1.607,84,105$} & \multicolumn{2}{|l|}{$1.031,84,105$} \\
\hline $\mathrm{P}$ value & \multicolumn{2}{|l|}{0.0106} & \multicolumn{2}{|l|}{0.4388} \\
\hline $\mathrm{P}$ value summary & \multicolumn{2}{|l|}{$*$} & \multicolumn{2}{|l|}{$\mathrm{Ns}$} \\
\hline $\begin{array}{l}\text { Are variances significantly } \\
\text { different? }\end{array}$ & \multicolumn{2}{|l|}{ Yes } & \multicolumn{2}{|l|}{ No } \\
\hline
\end{tabular}


Table 2: Showing statistics of Maxillary sinus AP diameter \& Width.

\begin{tabular}{|c|c|c|c|c|}
\hline \multirow[t]{2}{*}{ Statistics } & \multicolumn{2}{|c|}{ Sinus AP diameter (in cm) } & \multicolumn{2}{|c|}{ Sinus Width (in cm) } \\
\hline & Male & Female & Male & Female \\
\hline $\mathrm{N}$ & 106 & 85 & 106 & 85 \\
\hline Mean \pm SD & $\begin{array}{l}3.643 \pm \\
0.426\end{array}$ & $\begin{array}{l}3.493 \pm \\
0.414\end{array}$ & $\begin{array}{l}2.404 \pm \\
0.471\end{array}$ & $\begin{array}{l}2.39 \pm \\
0.438\end{array}$ \\
\hline Mean \pm SEM & $3.643 \pm 0.03997$ & $3.493 \pm 0.04331$ & $2.404 \pm 0.04389$ & $2.39 \pm 0.0458$ \\
\hline P value(Two-tailed) & \multicolumn{2}{|l|}{$0.0120 *$} & \multicolumn{2}{|l|}{$0.8239=\mathrm{Ns}$} \\
\hline Difference between means & \multicolumn{2}{|l|}{$0.1500 \pm 0.05914$} & \multicolumn{2}{|l|}{$0.01425 \pm 0.06391$} \\
\hline $\begin{array}{l}\text { Are means signif. different? } \\
(P<0.05)\end{array}$ & \multicolumn{2}{|l|}{ Yes } & \multicolumn{2}{|l|}{ No } \\
\hline $\mathrm{t}, \mathrm{df}$ & \multicolumn{2}{|l|}{$\mathrm{t}=2.536 \mathrm{df}=189$} & \multicolumn{2}{|l|}{$\mathrm{t}=0.2229 \mathrm{df}=189$} \\
\hline $95 \%$ confidence interval & \multicolumn{2}{|l|}{0.03408 to 0.2659} & \multicolumn{2}{|l|}{-0.1110 to 0.1395} \\
\hline R squared & \multicolumn{2}{|l|}{0.03291} & \multicolumn{2}{|l|}{0.0002628} \\
\hline $\begin{array}{l}\text { Average }(\mathrm{M}+\mathrm{F}) \\
\text { Mean } \pm \text { SD }\end{array}$ & \multicolumn{2}{|l|}{$\begin{array}{l}3.567 \pm \\
0.42\end{array}$} & \multicolumn{2}{|l|}{$2.397 \pm$} \\
\hline
\end{tabular}

* significant; Ns - not significant

Table $3 \& 4$ shows the correlation of bizygomatic distance with with maxillary sinus dimensions in male \& female respectively. They all were significantly correlated but it was found that the most important and the strongest correlated variable with bizygomatic distance was the intermaxillary distance $(r=0.3037)$ in male \& AP diameter of sinus $(r=0.5980)$ in female.

Table 3: Correlation of Bizygomatic distance with maxillary sinus dimensions in Male:

\begin{tabular}{|l|l|l|l|}
\hline BiZygomatic correlation with & Avr. Sinus AP diameter & Avr. Sinus Width & Intermaxillary distance \\
\hline Pearson r & 0.2735 & 0.2336 & 0.3037 \\
\hline 95\% confidence interval & 0.08729 to 0.4413 & 0.04475 to 0.4063 & 0.1199 to 0.4675 \\
\hline P value (two-tailed) & 0.0046 & 0.0160 & 0.0015 \\
\hline P value summary & $* *$ & $*$ & $* *$ \\
\hline $\begin{array}{c}\text { Is the correlation significant? } \\
\text { (alpha=0.05) }\end{array}$ & Yes & Yes & Yes \\
\hline R squared & 0.07482 & 0.05455 & 0.09226 \\
\hline
\end{tabular}

Avr. $=$ average

Table 4:Correlation of Bizygomatic distance with maxillary sinus dimensions in Female:

\begin{tabular}{|l|l|l|l|}
\hline BiZygomatic correlation with & Avr. Sinus AP diameter & Avr. Sinus Width & Intermaxillary distance \\
\hline Pearson $\mathrm{r}$ & 0.5980 & 0.5065 & 0.4647 \\
\hline $\mathrm{P}$ value (two-tailed) & $\mathrm{P}<0.0001$ & $\mathrm{P}<0.0001$ & $\mathrm{P}<0.0001$ \\
\hline $\mathrm{P}$ value summary & $* * *$ & $* * *$ & $* * *$ \\
\hline $\begin{array}{l}\text { Is the correlation significant? } \\
\text { (alpha }=0.05 \text { ) }\end{array}$ & Yes & Yes & Yes \\
\hline $\mathrm{R}$ squared & 0.3576 & 0.2566 & 0.2160 \\
\hline
\end{tabular}

\section{Discussion}

In this study the overall average dimensions of each parameter was statistically greater for males compare with females. The mean \pm SD of Bizygomatic distance in male was $9.55 \pm 0.41 \mathrm{~cm} \&$ in female was $9.26 \pm 0.52 \mathrm{~cm} \&$ the total average $(\mathrm{M}+\mathrm{F})$ was $9.41 \pm 0.462 \mathrm{~cm}$ which were significant statistically $(\mathrm{p}<0.0001) \&$ it shows that this is a very strong parameter which can be used for gender determination for the given region. In Igbo people in South East Nigeria (Ewunonu EO)[6] the bizygomatic diameter was $13.73 \pm 0.79 \mathrm{~cm}$ for male \& $13.07 \pm 0.77 \mathrm{~cm}$ for female \& the average was $13.50 \mathrm{~cm}$ which was very greater than our results probably due to different region \& race. In Ariji Y et al [7] study the width of the adult sinus correlated with the interzygomatic buttress distance and body weight but it was not used as a measure for sex estimation. Staley RL [8], compared myotonic dystrophy patients to similar normal subjects which showed that myotonic subjects differed from normal subjects in bizygomatic face width along with other cephalometric measures. Bizygomatic pinching is a feature of Fragile X syndrome (Laxova R) [9]. In Chung CS [10] study bizygomatic diameter appears to behave as a partial dominant trait $\&$ the racial mean of bizygomatic diameter, or the ratio of this measure to head length, were found to have a relationship with the racial incidences of cleft lip with or without cleft palate. According to Latta GH [11]study, in edentulous patients, the widths varied widely, even when the population was separated into groups by sex and/or race. Black men differed significantly from black women, white women and white men in interalar and bizygomatic widths.

The AP diameter (mean \pm SD) in male was $36.43 \pm 4.26 \mathrm{~mm}$ which were significantly $(\mathrm{p}<0.05)$ larger than for female which was $34.93 \pm 4.14 \mathrm{~mm}$. The total $(\mathrm{M}+\mathrm{F})$ average AP diameter was $35.67 \pm 4.2 \mathrm{~mm}$. In Baweja et al [12] study the average AP diameter for male was $34.1 \pm 5.1 \mathrm{~mm} \&$ for female was $33.0 \pm 5.6 \mathrm{~mm}$. The total average AP $(\mathrm{M}+\mathrm{F})$ was $33.5 \pm 5.3 \mathrm{~mm}$, which were very close to our results. This is due to same ethnic group 
study belonging to same region; whereas studies done by Teke HY et al [1] had average sinus AP dia $43.14 \pm 7.84 \mathrm{~mm}$ for male, $37.7 \pm 5.85 \mathrm{~mm}$ for female $\& 40.42 \pm 6.84 \mathrm{~mm}$ as the total $\mathrm{M}+\mathrm{F}$ average which were larger than our results. By Aasma T. et al [13] study the results were $39.35 \pm 3.75 \mathrm{~mm}$ for male, $36.95 \pm 3.9 \mathrm{~mm}$ for female \& $38.15 \pm 3.83 \mathrm{~mm}$ as the total $\mathrm{M}+\mathrm{F}$ average which were also larger than our results. This difference was probably due to different study region \& different ethnic \& racial factors. In our study the sinus Width in Male (mean \pm SD) was $24.04 \pm 4.71 \mathrm{~mm} \&$ for Female $23.9 \pm 4.38 \mathrm{~mm}$ which were not significant statistically. The total average width $(\mathrm{M}+\mathrm{F})$ was $23.97 \pm 4.55 \mathrm{~mm}$. The average sinus Width in Baweja et al [12] study for male was $21.8 \pm 3.4 \mathrm{~mm} \&$ for female was $21.6 \pm 3.7 \mathrm{~mm}$, Total (M+F) average width was $21.7 \pm 3.5 \mathrm{~mm} \&$ by Aasma T. et al [13] the results were $25.15 \pm 4.2 \mathrm{~mm}$ for male, $22.85 \pm 3.6 \mathrm{~mm}$ for female \& $24 \pm 3.9 \mathrm{~mm}$ as the total $\mathrm{M}+\mathrm{F}$ average which were very close to our results. In Teke HY et al [1] study the average sinus width was $27.04 \pm 5.49 \mathrm{~mm}$ for male, $24.36 \pm 3.795 \mathrm{~mm}$ for female $\& 25.7 \pm 4.64 \mathrm{~mm}$ as the total $\mathrm{M}+\mathrm{F}$ average which were larger than our results. This difference was probably due to combination of many factors but mainly due to different ethnic \& racial groups with different body stature, skeletal size, height \& physique of an individual; environmental conditions \& pneumatization [14] process of sinus in different age \& sex groups.

\section{Conclusion}

It was concluded that the measured dimensions of male was found to be larger than those of female \& this difference was statistically significant for Bizygomatic distance $(p<0.0001)$ \& AP diameter of maxillary sinus $(\mathrm{p}<0.05)$. The strongest correlated variable with bizygomatic distance was the intermaxillary distance $(\mathrm{r}=$ $0.3037)$ in male \& AP diameter of sinus $(r=0.5980)$ in female. The results obtained were comparable to the previous studies \& can be used as an aid in forensic anthropology for gender determination to some extent. We can conclude that Computerized Tomography measurements of bizygomatic distance \& maxillary sinus dimensions may be useful to support gender determination in forensic medicine when other methods are inconclusive.

\section{Reference}

[1] Teke HY, Duran S, Canturk N, Canturk G. Determination of gender by measuring the size of the maxillary sinuses in computerized tomography scans. Surg Radiol Anat 2007;166:42-84 .

[2] Jasim HH, Al-Taei JA. Computed tomographic measurement of maxillary sinus volume and dimension in correlation to the age and gender (comparative study among individuals with dentate and edentulous maxilla). J Bagh Coll Dentistry 2013;25(1):87-93.

[3] Amin MF, Hassan EI. Sex identification in egyptian population using multidetector computed tomography of the maxillary sinus, http://dx.doi.org/10.1016/j.jflm.2011.10.005,Cited by in Scopus(0).

[4] Lerno P. Identification par le sinus maxillaire. Odontol Leg 1983;216:39.

[5] Fernandez JMS, Escuredo JAA, Rey ASD, Montoya FSM. Morphometric study of the paranasal sinuses in normal and pathological conditions. Acta Oto-laryngol 2000;120:273-278.

[6] Ewunonu EO, Anibeze CIP. Anthropometric study of the Facial Morphology in a South-Eastern Nigerian Population. Hum Bio Rev. 2013;2(4):314- 323

[7] Ariji Y, Ariji E, Yoshiura K, Kanda S. Computed tomographic indices for maxillary sinus size in comparison with the sinus volume. Published Online: January 28, 2014; http://dx.doi.org/10.1259/dmfr.25.1.9084281.

[8] Staley RN, Bishara SE, Hanson JW, Nowak AJ. Craniofacial development in myotonic dystrophy. American Cleft PalateCraniofacial Association 1992;29(5):456-62.

[9] Laxova R. Fragile X syndrome in: Advances in pediatrics, University of Wisconsin, Madison 1994;41:305-42.

[10] Chung CS, Runck DW, Bilben SE, Kau MC. Effects of interracial crosses on cephalometric measurements. American journal of physical anthropology 1986;69(4):465-72.

[11] Latta GH, Weaver JR, Conkin JE. The relationship between the width of the mouth, interalar width, bizygomatic width, and interpupillary distance in edentulous patients. Journal of prosthetic dentistry 1991;65(2):250-4.

[12] Baweja S, Dixit A, Baweja S. Study of age related changes of maxillary air sinus from its anteroposterior, transverse and vertical dimensions using Computerized Tomographic (CT) scan. IJBR 2013;04 (01).

[13] Uthman AT, Al-Rawi NH, Al-Naaimi AS, Al-Timimi JF. Evaluation of maxillary sinus dimensions in gender determination using helical CT Scanning. Journal of forensic sciences 2011;56( 2):403-408.

[14] Sharan A, Madjar D. Maxillary sinus pneumatization following extractions: a radiographic study. Int J Oral and Maxillofacial Implants 2008; 23:48-56. 